\title{
Anomalous SAXS Study on Structural Inhomogeneity in Amorphous $\mathrm{Zr}_{33} \mathbf{Y}_{27} \mathbf{A l}_{15} \mathbf{N i}_{25}$ Alloy
}

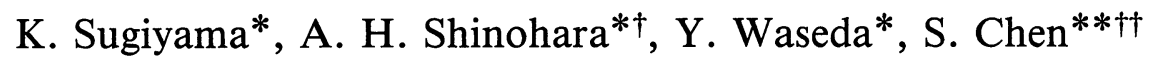 \\ and A. Inoue** \\ *Institute for Advanced Materials Processing, Tohoku University, Sendai 980-77, Japan \\ **Institute for Materials Research, Tohoku University, Katahira Sendai 980-77, Japan
}

\begin{abstract}
An anomalous small angle X-ray scattering (anomalous SAXS) method has been applied to obtain a possible origin of structural inhomogeneity in amorphous $\mathrm{Zr}_{33} \mathrm{Y}_{27} \mathrm{Al}_{15} \mathrm{Ni}_{25}$ alloy annealed at $773 \mathrm{~K}$ for $300 \mathrm{~s}$. The remarkable decrease in intensity is detected for $\mathrm{Ni}$ and $\mathrm{Zr}$ whereas an increase is clearly observed for $\mathrm{Y}$, when the incident energy approaches to the respective $K$-absorption edge. Several models have been tested for describing these new experimental data and the Yrich phase is suggested to be one of the possible origins for structural inhomogeneity by explaining the anomalous SAXS intensity variations at three absorption edges of $\mathrm{Ni}, \mathrm{Y}$ and $\mathrm{Zr}$.
\end{abstract}

Keywords: anomalous $X$-ray scattering, small angle scattering, structural inhomogeneity, amorphous alloy, synchrotron radiation

\section{Introduction}

Recently, Inoue and his co-workers ${ }^{(1)}$ have found two glass transition temperatures as well as a wide supercooled liquid region in an amorphous $\mathrm{Zr}_{33} \mathrm{Y}_{27} \mathrm{Al}_{15} \mathrm{Ni}_{25}$ alloy. The origin of this particular nature has been attributed to the insoluble character of yttrium and zirconi$\mathrm{um}^{(1)(2)}$, and this suggests the structural inhomogeneity in the amorphous state. The local structural information of this amorphous alloy in both as-quenched and annealed states has been obtained by the wide-angle X-ray diffraction technique ${ }^{(2)(3)}$. However, the analysis of local structure is often not enough for discussing the nature of structural inhomogeneity in the system of interest.

The small-angle X-ray scattering (SAXS) method is one way to clarify the structural inhomogeneity in amorphous alloys. However, it is frequently known that a broad small-angle X-ray scattering signal can be fitted by a variety of models almost equally well, for example; quasi-dislocations, small clusters of crystallized material, compositional fluctuations or bubbles. With respect to such inconvenience, the use of anomalous X-ray scattering will bring a breakthrough by permitting the scattering contrast of a desired element. Namely by using the significant variation of the atomic scattering factor near the absorption edge of one of the constituent elements, it is

\footnotetext{
$\dagger$ Research Scientist, Tohoku University. Present address: Kimura Metamelt Project, ERATO, JRDC, Yagiyama-minami, Sendai 982, Japan.

t† Research Scientist, Tohoku University.
}

possible to determine the origin of the particular SAXS peak $^{(4)(5)}$.

The main purpose of this paper is to describe the structural inhomogeneity developed in the supercooled liquid region of amorphous $\mathrm{Zr}_{33} \mathrm{Y}_{27} \mathrm{Al}_{15} \mathrm{Ni}_{25}$ alloy by using anomalous SAXS technique.

\section{Experimental}

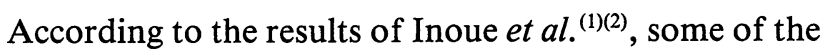
amorphous ribbons of $\mathrm{Zr}_{33} \mathrm{Y}_{27} \mathrm{Al}_{15} \mathrm{Ni}_{25}$ (15 mm long, 5 $\mathrm{mm}$ wide, $0.2 \mathrm{~mm}$ thick) were annealed at $773 \mathrm{~K}$ in a continuously evacuated silica glass tube for various length of time up to $900 \mathrm{~s}$. It may be worth noting that a sample was sandwiched between two aluminum plates and wrapped with aluminum foil in this annealing process. This makes a suitable flat sample for the X-ray scattering measurements.

The conventional measurements for amorphous $\mathrm{Zr}_{33} \mathrm{Y}_{27} \mathrm{Al}_{15} \mathrm{Ni}_{25}$ alloy were made by the wide angle $\mathrm{X}$-ray diffraction and small angle X-ray scattering (SAXS) with a goniometer with three divergent slits, using $\mathrm{Cu} K \alpha$ radiation. Anomalous SAXS measurements were carried out with synchrotron radiation at the Photon Factory of the National Laboratory for High Energy Physics, Tsukuba, Japan. The experimental set up is similar to that reported in Ref. (6) except for a pair of divergent slits so as to reduce the so-called parasitic scattering effect. The incident beam was selected by the $\mathrm{Si}(111)$ double crystal monochromator, and its intensity was monitored by the ionization chamber placed in front of a sample. Anomalous SAXS data were collected at 30, 100 and 300 
$\mathrm{eV}^{\dagger}$ below $\mathrm{Ni}$ and $\mathrm{Y} K$-absorption edges. For $\mathrm{Zr} K$-edge, incident energies of 30, 100 and $200 \mathrm{eV}$ below the absorption edge were selected, since the effect of an EXAFS oscillation on the anomalous dispersion terms of $\mathrm{Y}$ is not negligible in this case. The scattering intensities from samples were measured by using a portable pure Ge solid state detector. The measurements for $\mathrm{Al}-6.7$ at $\% \mathrm{Zn}$ alloy was also made as a reference sample, where no anomalous dispersion effect should be observed in the energy range of present interest. The data shown here are scaled by the intensity of ion chamber ${ }^{(6)(7)}$ followed by due corrections for the sample absorption, the background intensity and the aperture of the receiving slit, including escape correction for the counter probe. It is worth mentioning that further conversion of these results to the absolute unit can be made by multiplication by a constant factor.

\section{Results and Discussion}

Figure 1 shows the wide angle $\mathrm{X}$-ray diffraction profiles of the samples annealed at $773 \mathrm{~K}$ for various length of time up to $900 \mathrm{~s}$. Samples annealed for less than $600 \mathrm{~s}$ essentially keep the typical amorphous diffraction pattern, although the first and second broad peaks become sharper by annealing. On the other hand, the sample starts to crystallize by annealing for more than $900 \mathrm{~s}$ and the good coincidence with the information of $\mathrm{Al}_{3} \mathrm{Zr}_{5}$ (JCPDS No. 12-674) has been suggested. It may also be helpful to recall the local structural information obtained from the environmental RDFs of this particular amorphous $\mathrm{Zr}_{33} \mathrm{Y}_{27} \mathrm{Al}_{15} \mathrm{Ni}_{25}$ alloy on both the as-quenched and annealed states ${ }^{(3)}$. The essential points are as follows. The local ordering structure around $\mathrm{Y}$ and $\mathrm{Ni}$ are developed during the exothermic reaction at temperature between $T_{\mathrm{g} 1}(658 \mathrm{~K})$ and $T_{\mathrm{g} 2}(772 \mathrm{~K})$. This contrasts to the change in environment for $\mathrm{Zr}$, where the structural ordering around $\mathrm{Zr}$ varies into the slightly random one by anneal-

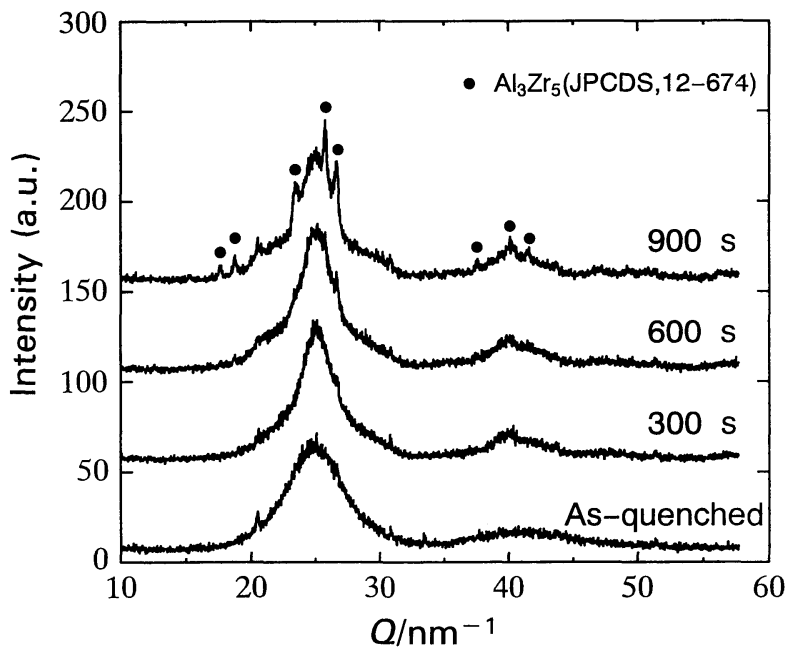

Fig. 1 X-ray diffraction intensity patterns of $\mathrm{Zr}_{33} \mathrm{Y}_{27} \mathrm{Al}_{15} \mathrm{Ni}_{25}$ alloy for the samples annealed at $773 \mathrm{~K}$ for various lengths of time.

$\dagger 1 \mathrm{eV}=1.60218 \times 10^{-19} \mathrm{~J}$ ing. In addition, the local structural information around $\mathrm{Y}$ and $\mathrm{Zr}$ in this amorphous alloy suggests the coordination numbers of $\mathrm{Y}-\mathrm{Y}$ and $\mathrm{Zr}-\mathrm{Zr}$ pairs increase at the cost of $\mathrm{Y}-\mathrm{Zr}$ pair by annealing and this is consistent with the precipitation of the nanoscale Y-rich phase ${ }^{(2)(3)}$ and the crystallization of the $\mathrm{Al}_{3} \mathrm{Zr}_{5}$ phase. These precipitates are quite likely to produce structural inhomogeneity in the amorphous $\mathrm{Zr}_{33} \mathrm{Y}_{27} \mathrm{Al}_{15} \mathrm{Ni}_{25}$ alloy.

Figure 2 shows the conventional SAXS data. In the small $Q$ region, a maximum of the scattered intensity is observed at $Q=0.65 \mathrm{~nm}^{-1}$, indicating the existence of spatial correlations with a characteristic distance of about $10 \mathrm{~nm}$. In the case of a sample annealed at $773 \mathrm{~K}$ for more than $600 \mathrm{~s}$, a drastic increase in intensity is observed near the angular origin. This is consistent with the observation related to the crystallization behavior of $\mathrm{Al}_{3} \mathrm{Zr}_{5}$ phase. Then, the sample annealed at $773 \mathrm{~K}$ for $300 \mathrm{~s}$ is selected as an appropriate condition for discussing the structural inhomogeneity in the present work.

Figure 3 shows the measured anomalous SAXS intensities for amorphous $\mathrm{Zr}_{33} \mathrm{Y}_{27} \mathrm{Al}_{15} \mathrm{Ni}_{25}$ alloy annealed at 773 $\mathrm{K}$ for $300 \mathrm{~s}$. Although the positional resolution of anomalous SAXS signals is not sufficient, the anomalous dispersion effect is clearly detected in Fig. 3 such as the remarkable decrease of the intensity for $\mathrm{Ni}$ and $\mathrm{Zr}$ when the incident X-ray approaches the respective $K$-absorption edge. On the contrary, the SAXS intensity for Y increases when the incidence approaches to the edge. The inserts show the SAXS intensities of Al-6.7 at $\% \mathrm{Zn}$ alloy used as a reference sample at the same energies. No significant change is detected for $\mathrm{Al}-6.7 \% \mathrm{Zn}$ alloy and this clearly supports that the present anomalous SAXS measurement works well. The variation in intensity of the anomalous SAXS peak for $\mathrm{Zr}_{33} \mathrm{Y}_{27} \mathrm{Al}_{15} \mathrm{Ni}_{25}$ between two curves obtained at two energies of $-30 \mathrm{eV}$ and $-300 \mathrm{eV}$ $(-200 \mathrm{eV}$ for the $\mathrm{Zr}$ case) were estimated as $+18 \%$, $-21 \%$ and $+50 \%$ for $\mathrm{Ni}, \mathrm{Y}$ and $\mathrm{Zr}$, respectively.

Based on these new information obtained by the anomalous SAXS technique, it is quite charanging to find a possible origin of the structural inhomogeneity related to the SAXS intensity of this particular amor-

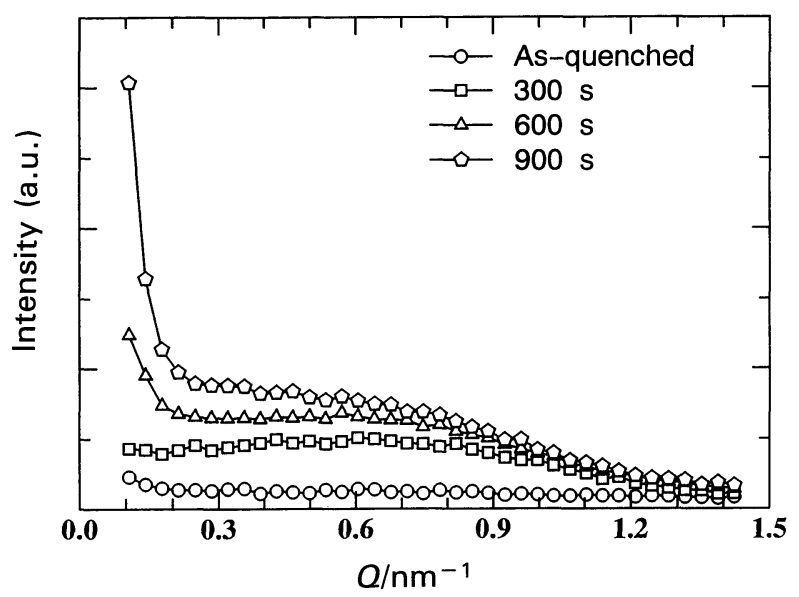

Fig. 2 SAXS intensity patterns of $\mathrm{Zr}_{33} \mathrm{Y}_{27} \mathrm{Al}_{15} \mathrm{Ni}_{25}$ alloy for the samples annealed at $773 \mathrm{~K}$ for various lengths of time. 

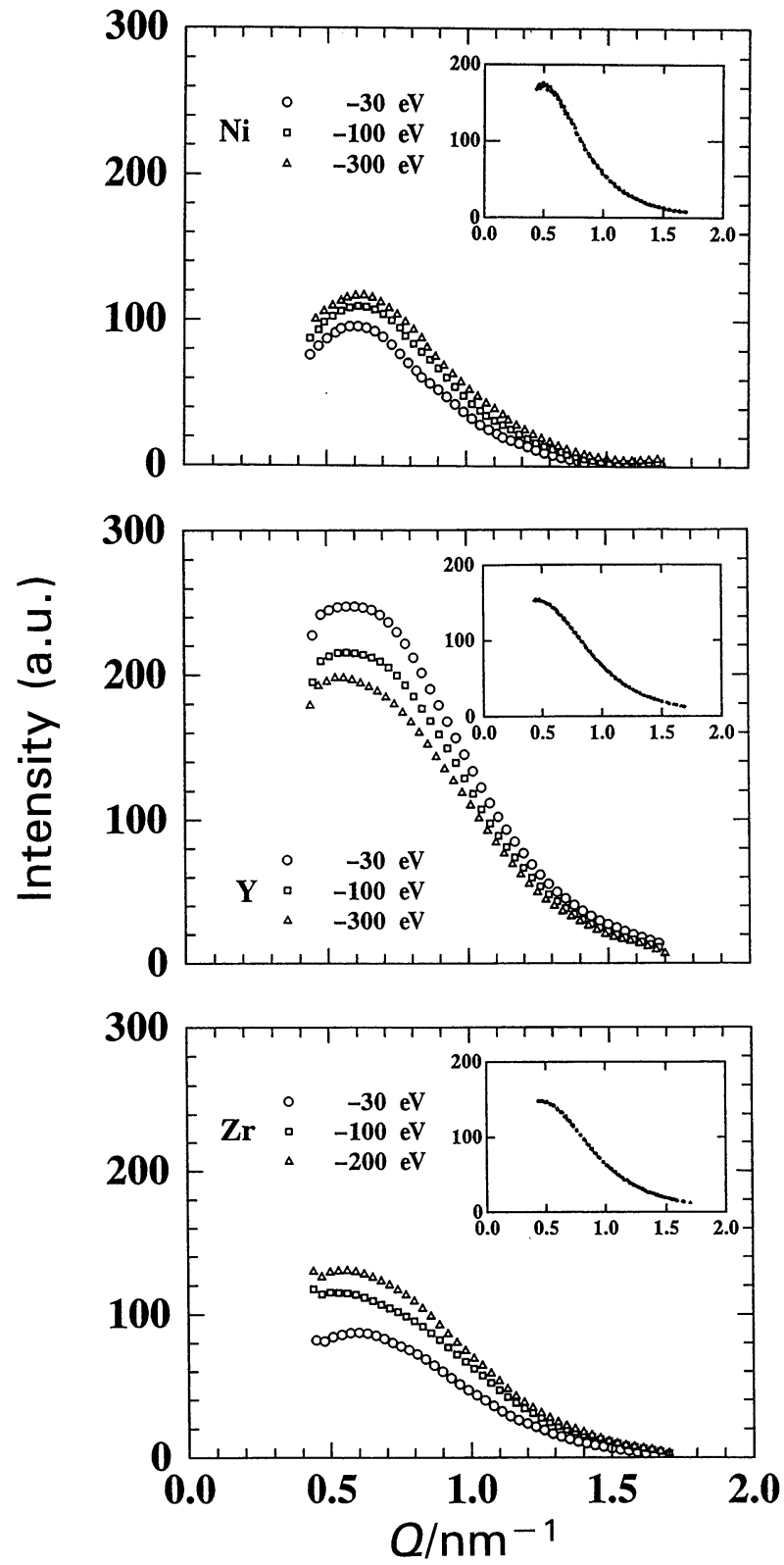

Fig. 3 Energy dependence of the SAXS intensity near the Ni, Y and $\mathrm{Zr} K$-absorption edge for the amorphous $\mathrm{Zr}_{33} \mathrm{Y}_{27} \mathrm{Al}_{15} \mathrm{Ni}_{25}$ alloy annealed at $773 \mathrm{~K}$ for $300 \mathrm{~s}$.

phous alloy, by considering the interference effect due to fluctuation in composition and density attributed to a certain precipitate such as $\mathrm{Al}_{3} \mathrm{Zr}_{5}$.

Assuming that the amorphous alloy annealed at $773 \mathrm{~K}$ consists of two phases of the crystalline $\mathrm{Al}_{3} \mathrm{Zr}_{5}$ precipitate and the amorphous matrix, the total integrated intensity $Q_{0}$ is proportional to the square of the contrast of effective electronic density of $\rho$, as follows ${ }^{(8)}$ :

$$
Q_{0}=4 \pi \int_{0}^{\infty} Q^{2} I(Q) \mathrm{d} Q=(\Delta \rho)^{2}
$$

where $\Delta \rho$ is the electron density difference between two phases. The volume fraction of inhomogenious region is constant for a given sample in the present measurement, thus the integrated intensity is proportional to the square of the average electron density difference. Furthermore, the integrated intensity may also be proportional to $\left((\Delta\langle f\rangle)^{2}\right)$, which corresponds to the difference of the averaged atomic scattering factor between two phases.

The intensity variation at three absorption edges were calculated by using the anomalous dispersion terms ${ }^{(4)}$ coupled with the measured density of $5.62 \mathrm{Mg} / \mathrm{m}^{3}$ for amorphous $\mathrm{Zr}_{33} \mathrm{Y}_{27} \mathrm{Al}_{15} \mathrm{Ni}_{25}$ alloy in the annealed state. The calculated variation of intensity at $\mathrm{Y} K$-edge indicates the decreasing nature when the incident energy approaches to the absorption edge and this is inconsistent with the experimental result. Similarly the calculated variation at $\mathrm{Zr}$ $K$-edge also contradicts the experimental variation. This clearly indicates that $\mathrm{Al}_{3} \mathrm{Zr}_{5}$ crystalline phase is not accepted as a possible origin for structural inhomogeneity in this amorphous alloy. Therefore, the structural inhomogeneity giving rise to the present SAXS signal should be linked to another combination.

Let us recall the local structural change of this amorphous alloy induced by annealing ${ }^{(3)}$. The chemical fluctuation of Y-rich precipitate is suggested to exist, and this leads to imagine that crystalline phase such as $\mathrm{Y}_{60} \mathrm{Al}_{40}$ or amorphous phase such as $\mathrm{Y}_{60} \mathrm{Al}_{15} \mathrm{Ni}_{25}$ is segregated from the $\mathrm{Zr}_{33} \mathrm{Y}_{27} \mathrm{Al}_{15} \mathrm{Ni}_{25}$ matrix. The anomalous SAXS intensities were again calculated by assuming these contributions with the density values of 4.36 and the measured one of $4.95 \mathrm{Mg} / \mathrm{m}^{3}$ for the crystalline $\mathrm{Y}_{60} \mathrm{Al}_{40}$ and amorphous $\mathrm{Y}_{60} \mathrm{Al}_{15} \mathrm{Ni}_{25}$ alloys, respectively. The results are summarized in Table 1 together with the experimental results. Present combinations provide the correct sign for the intensity variation at three absorption and the $\mathrm{Y}_{60} \mathrm{Al}_{15} \mathrm{Ni}_{25}$ case is in relatively good accordance with the experimental data, although the quantitative agreement between calculation and experiment at the $\mathrm{Ni}$ edge is poor. Further calculation should be required by considering not only the atomic volume of the precipitates but also the precise value of integrated intensity, but it is at the present time beyond the limitation of the experimental uncertainty. Nevertheless, the usefulness of the anomalous SAXS method is clearly demonstrated by obtaining the origin of structural inhomogeneity in the amorphous $\mathrm{Zr}_{33} \mathrm{Y}_{27} \mathrm{Al}_{15} \mathrm{Ni}_{25}$ alloy. It is almost unsolved by the conventional SAXS technique alone. It would be interesting to extend this anomalous SAXS method to other subjects of structural inhomogeneity in materials, because the anomalous SAXS method is the alternative to the isotope substitution of neutron SAXS with the advantage that all measurements use the same sample.

Table 1 The variation of the scattered intensity when the incident energy leaves three absorption edge.

\begin{tabular}{lccc}
\hline \hline & $\mathrm{Ni}$ & $\mathrm{Y}$ & $\mathrm{Zr}$ \\
\hline & +18 & -21 & +50 \\
Experimental & +16 & -9 & +18 \\
$\mathrm{Y}_{60} \mathrm{Al}_{40} / \mathrm{Zr}_{33}$ & +4 & -21 & +59 \\
$\mathrm{Y}_{60} \mathrm{Al}_{15} \mathrm{Ni}_{25} / \mathrm{Zr}_{33}$ & +4 \\
\hline \hline
\end{tabular}

* $\mathrm{Y}_{60} \mathrm{Y}_{40} / \mathrm{Zr}_{33}$ means the segregation of $\mathrm{Y}_{60} \mathrm{Al}_{40}$ with the matrix of amorphous $\mathrm{Zr}_{33} \mathrm{Y}_{27} \mathrm{Al}_{15} \mathrm{Ni}_{25}$. 


\section{Acknowledgments}

The authors thank Prof. M. Nomura and Dr. K. Koyama in Photon Factory, National Laboratory for High Energy Physics, for their advise of AXS measurements (Proposal No. 93G269).

One of the authors (AHS) thanks to the Ministry of Education, Science and Culture, Japan for its financial support through the Monbusyo scholarship.

\section{REFERENCES}

(1) T. Zhang, A. Inoue, S. Chen and T. Masumoto: Mater. Trans., JIM, 33 (1993), 143.
(2) A. Inoue, S. Chen, E. Oikawa, T. Zhang and T. Masumoto: Mater. Letters, 16 (1993), 108.

(3) E. Matsubara, K. Sugiyama, A. H. Shinohara and Y. Waseda: Mat. Sci. Eng., A179/A180 (1994), 444.

(4) Y. Waseda,: Novel Application of Anomalous (Resonance) X-Ray Scattering for Structural Characterization of Disordered Materials, Springer-Verlag, Berlin Heidemberg, (1984).

(5) (e.g.) A. H. Shinohara, K. Sugiyama and Y. Waseda: High. Temp. Mat. Pro., 10 (1993), 159.

(6) Y. Waseda, E. Matsubara and K. Sugiyama: Sci Rep. RITU, A34 (1998), 1.

(7) E. Matsubara and P. Georgopoulos: J. Appl. Cryst., 18 (1985), 377.

(8) P. Goudeau, A. Naudon, A. Chamberod, B. Rodmacq and C. E. Williams: Europhys. Lett., 3 (1987), 269. 